\title{
Familial centronuclear myopathy
}

\author{
W. G. BRADLEY ${ }^{1}$, D. L. PRICE, AND C. K. WATANABE \\ From the Department of Neuropathology, Massachusetts General Hospital; the Department of Neurology, \\ Harvard Medical School, Boston, Mass.; and the Department of Medicine, Highland General Hospital, \\ Oakland, California, U.S.A.
}

SUMMARY The clinical and histological features of two Negro brothers with a centronuclear myopathy are described. They bring to 19 the number of cases now reported with this constellation of physical signs and pathological changes in the muscles. A review of these patients suggests the existence of several different diseases causing this picture, though presumably the underlying biochemical defects are closely related. It is concluded that these myopathies are degenerative rather than due to arrest of foetal muscle maturation.

Spiro, Shy, and Gonatas (1966) described a boy with a congenital myopathy affecting all skeletal muscles, and especially causing external ophthalmoplegia, ptosis, and facial weakness. Up to $85 \%$ of the skeletal muscle fibres had central nuclei. The authors suggested that these fibres represented foetal myotubes persisting into adolescence, and named the condition 'myotubular myopathy'. Since then, 16 further cases believed to be suffering from the same condition have been reported (see Table 1). The theory of the persistence of myotubes has not won universal acceptance, and the term 'centronuclear myopathy' is to be preferred.

We have studied a further pair of brothers with this condition, and record our findings in this report. A review of the 19 total cases shows a lack of uniformity in the age of onset, clinical features, and histochemical characteristics. The question of whether more than one disease entity is included will be discussed.

\section{CASE 1}

G.L., a negro patient aged 34 years (Highland General Hospital No. 10-06-88-9) developed normally until the age of 8 years, when weakness of the lower limbs developed rapidly. A diagnosis of 'infantile paralysis' was made. Although bedridden for nine months, he gradually regained the ability to walk. From that time, generalized poor muscular development was associated with progressive weakness, easy fatiguability, and shortness of breath. At the age of 17, bilateral ptosis was noted, weak-

${ }^{1}$ Current address and address for reprints: Muscular Dystrophy Group Research Laboratories, Newcastle General Hospital, Newcastle upon Tyne, NE4 6BE. ness equally affected proximal and distal muscles, and tendon reflexes were absent. He was confined to a wheelchair and unable to sit without assistance. A left gastrocnemius muscle biopsy was obtained (see below).

Difficulty in clearing tracheobronchial secretions caused repeated bouts of bronchopneumonia. By 25 years of age, bilateral ptosis was severe, though extraocular movements were full. There was weakness of facial, palatal, and lingual movements. The temporalis muscles were atrophic, but the masseter, sternomastoid, and upper trapezius muscles were of normal bulk. Movements of the extremities were extremely weak, especially proximally, and the limb girdle muscles particularly atrophic. The respiratory muscles were weak, with a thoracic kyphoscoliosis. A cardiac ejection systolic murmur was heard. The ECG showed right ventricular hypertrophy.

The muscle weakness worsened, and at 34 years of age he was readmitted to the hospital because of dyspnoea. He was still able to feed himself and roll over in bed, but could do little else. A few days after admission he died of aspiration.

Post-mortem examination disclosed 'bronchopneumonia, focal fibrosis of the myocardium, and a small colloid goitre. The skeletal muscles were pale and atrophic; the histological findings are described below. Numerous levels of the spinal cord showed no abnormality; the complement of motor neurones was normal. The smooth muscle of the gut, bladder, and blood vessels was normal.

\section{CASE 2}

A.L. was the elder brother of G.L. (case 1) (Napa State Hospital No. 40486. Clinical details were obtained from the Napa State Hospital records). He developed normally until the age of 15 years when, after a bout of pneumonia, he began dragging his left leg. At the age of 20 he was committed to the Napa State Hospital because of a 
progressive illness characterized by religious mania, delusions, and dementia. A diagnosis of dementia praecox was made. At that time he was noted to have extremely thin muscles, a waddling gait, and a kyphoscoliosis. The tendon reflexes were absent, and he exhibited Gower's sign. He was confined to a wheelchair by the age of 23 years and had hip contractures and foot drop. He was psychotic and incontinent. Bilateral ptosis was described at the age of 30 , though external ocular movements were not mentioned. He died at the age of 34 years of bronchopneumonia.

At necropsy the skeletal muscles were pale and atrophic. Sections from two (unstated) muscles showed changes similar to those in his brother's muscles (see below). The complement of motor neurones in the spinal cord was normal. The brain showed only anoxic changes. The smooth muscle of gut, bladder, and blood vessels, and the myocardium were normal.

\section{FAMILY HISTORY}

The parents of the two brothers (cases 1 and 2) were not known to have primary muscular disease, and there was no consanguinity in the family. The father, aged 83 years, has post-encephalitic Parkinson's disease and suffered a stroke after myocardial infarction. Apart from these conditions, he has no muscle atrophy or weakness. The mother had carcinoma of the cervix, a mammary duct papilloma,, $\mathbb{Q}$ and a toxic nodular goitre and died of chronic renal failure due to chronic pyelonephritis (necropsy wase not permitted). The skeletal musculature was normale at each examination. Of the 13 sibs of A.L. and 0 G.L., one was stillborn and three died aged from 6 to? 12 weeks. Further details concerning these children are not available. One sister died aged 45 of an acute $\stackrel{\vec{f}}{\overrightarrow{7}}$ asthmatic attack; she had no sign of muscular. disease. Three other sibs have bronchial asthma, and $\overrightarrow{\vec{F}}$ two hypertension, but none of the eight living sibs? has symptoms or signs of skeletal muscle disease. There are 27 members of the third generation aged 3 to 35 years; none have signs of myopathy.

\section{SKELETAL MUSCLE PATHOLOGY}

The diagnosis of centronuclear myopathy in this $\overrightarrow{\vec{A}}$ sibship was made in retrospect. Consequently this ${ }_{\sigma}$ study deals only with formalin-fixed paraffin wax-embedded material. The left gastrocnemius muscle biopsy obtained at age 17 years from case 1 consisted of uniformly small muscle fibres (average diameteric $20.8 \mu$ ) with $85 \%$ of fibres in transverse sectiongo having central nuclei and with some central petrit nuclear loss of myofibrils (Fig. 1). Subsarcolemmini

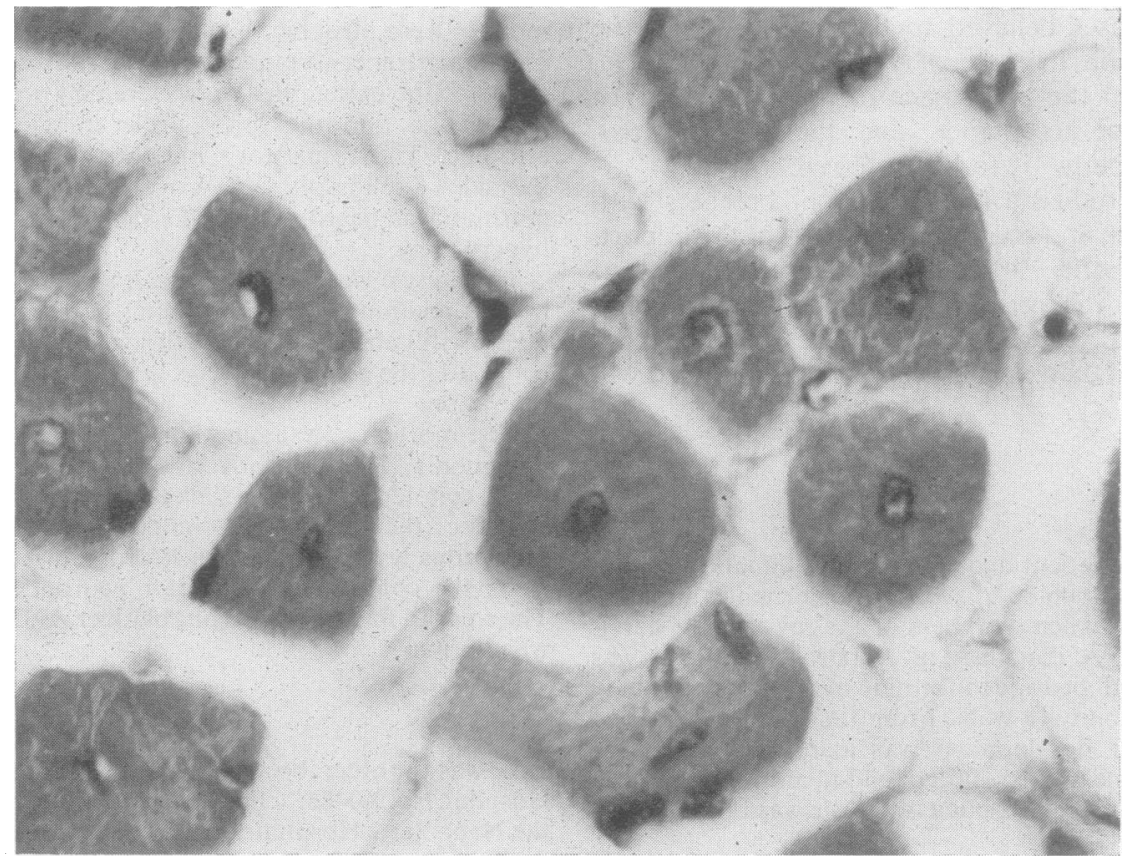

FIG. 1. Left gastrocnemius muscle biopsy from case 1 taken in 1951. Most of the fibres contain central nuclei. There is artefactual separation of fibres. $H$ and $E, \times 860$. 
nuclei were reduced in number. There was slight endomysial fibrosis. Necrosis, regeneration, and the grouped atrophy of denervation were absent.

The histological appearances of necropsy samples of the right and left gastrocnemius, quadriceps, iliopsoas, and deltoid muscles from case 1 , and of two unstated muscles from case 2 were very similar to those of the biopsy. Some muscles had extremely small fibres, and extensive endomysial fibrosis. In transverse section, many fibres had central areas devoid of myofibrils, and containing one to three central nuclei (Fig. 2). Subsarcolemnal nuclei were markedly reduced in number. Occasional fibres were grossly vacuolated. In longitudinal section, long chains of sarcolemmal nuclei were seen (Fig. 3). The extent of involvement varied strikingly, both between the same muscle on the two sides and between different muscles. The gastrocnemii, especially the right, were severely affected; the left iliopsoas and left deltoid muscles were more involved than those on the right, while the quadriceps muscles were relatively spared.

Transverse sections $6 \mu$ thick of each muscle from case 1 were viewed under an oil-immersion objective lens with a micrometer eyepiece. At least 150 fibres were measured. The average of the maximum and minimum diameter of each fibre was recorded. The fibre diameter spectra are shown in Fig. 1. The diameter of fibres of all muscles was unimodally distributed. The general smallness of the muscle fibres may be seen by comparison with control values (Table 2). The biopsy and necropsy specimens of left gastrocnemius muscle had very similar fibre diameters despite the 17 year interval. Muscles with a greater degree of fibre atrophy were more fibrotic.

The larger fibres in each muscle tended to have a higher proportion of central nuclei (Fig. 4). The proportion of fibres with central nuclei varied strikingly from muscle to muscle, and was only $27 \%$ in the necropsy specimen of the left gastrocnemius muscle compared with $85 \%$ in the biopsy of that muscle 17 years before, though in the necropsy specimen many fibres without central nuclei had central areas devoid of myofibrils. Of the fibres of two muscles from case $2,39 \%$ and $49 \%$ had central nuclei.

\section{DISCUSSION}

The two negro brothers described in this paper showed very similar clinical and pathological features to those first reported by Spiro et al. (1966),

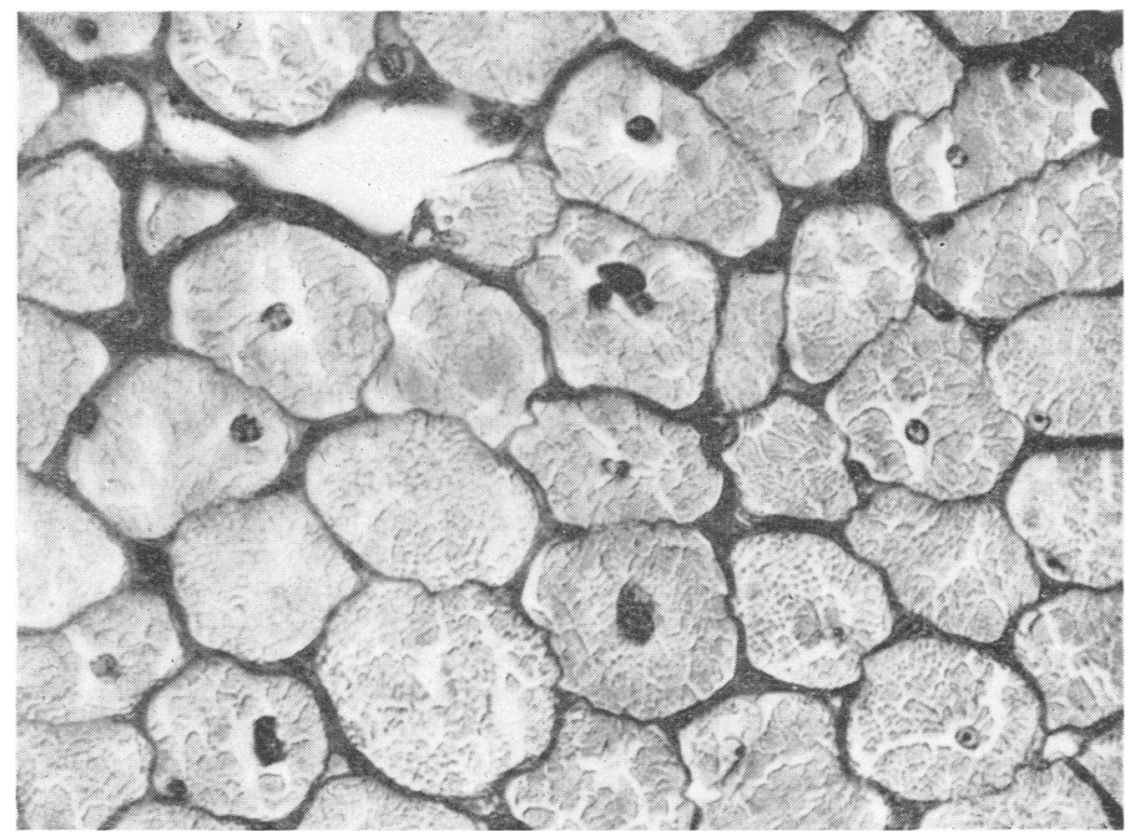

FIG. 2. Necropsy specimen of left quadriceps muscle of case 1. Many of the fibres have central nuclei, which are occasionally in clumps of two or three. There is marked endomysial fibrosis. PTAH, $\times 710$. 


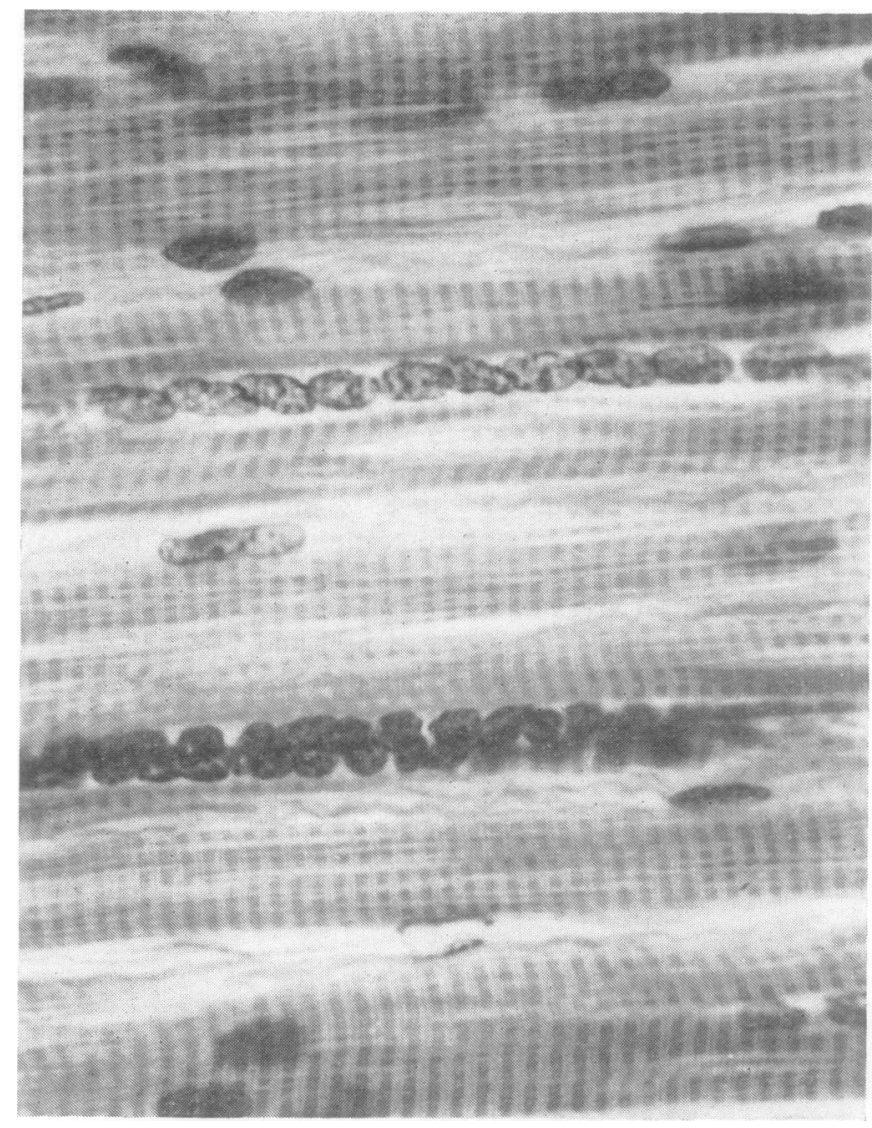

FIG. 3. As Fig. 2, showing chains of central nuclei in longitudinal section. $H$ and $E, \times 870$.

and since described in a further 16 cases (see Table 1). They had a severe progressive diffuse myopathy affecting facial muscles, with ptosis. The muscles showed marked reduction in the size of individual fibres, a high proportion of which contained central nuclei. This latter feature has prompted the descriptive title of centronuclear myopathy.

However a review of these 19 cases (Table 1) suggests a number of reasons for believing that several different disease entities are being grouped under this one title. Firstly the mode of inheritance has not been uniform. Most cases have been sporadic, though two pairs of sibs are included (Sher, Rimalovski, Athanassiades, and Aronson, 1967; present report); both sexes have been involved. The family reported by Wijngaarden, Fleury, Bethlem, and Meijer (1969) with six affected males clearly showed a sex-linked recessive mode of inheritance, suggesting a different genetically inherited biochemical defect from the remaining cases.

The age of onset of the myopathy has not been uniform. Most cases have been 'floppy babies', often with respiratory and feeding difficulties in the neonatal period, and reports that foetal movements $\mathbb{Q}$ were reduced. Three of these children have died in early infancy. Others have begun to have symptoms at the age of 2 to 4 years (Sher et al., 1967; Kinoshita and Cadman, 1968). The onset at age 8 and 15 years in the two brothers reported here is the oldest yet recorded. This different age pattern again suggests that we may be dealing with two or more? different diseases.

Ptosis and weakness of extraocular and facial muscles have been thought to be important clinical features of this disease, but one or more of these signs have been absent in several patients. The $\frac{\text { ? }}{9}$ females reported by Bethlem, Wijngaarden, Meijer, $>$ and Hülsmann (1969) and Bethlem, Wijngaarden, Mummenthaler, and Meijer(1970) had absence of all $N$
three features.

There have also been marked differences between $\mathbb{O}$ the histological and particularly histochemical $\tilde{\omega}$ 


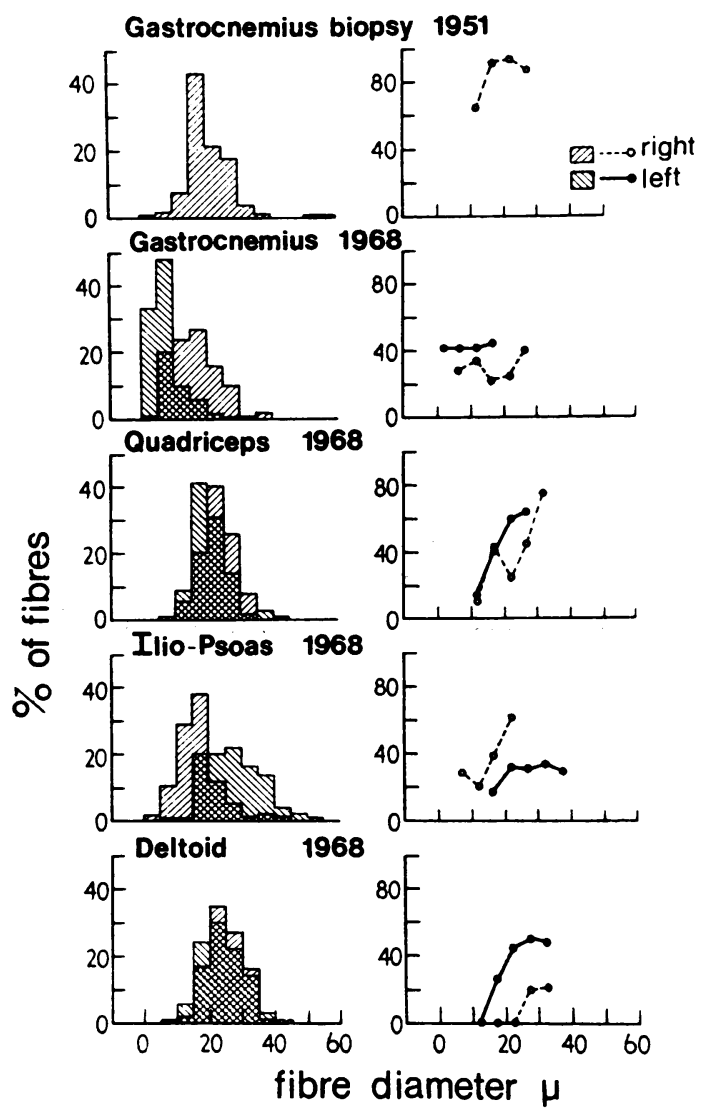

FIG. 4. Quantitative aspects of the histology of muscles from case 1. Left: histograms of the percentage distribution of transverse fibre diameter. Right: The percentage of fibres of each size with central nuclei in a $6 \mu$ thick transverse section.

features in these 19 cases. Several authors have illustrated a relatively uniform pattern of decrease of muscle fibre diameter, similar to the unimodal distribution shown in the present report. The histochemical studies in these reports demonstrated the clear increase in oxidative enzymes present in the central sarcoplasm between the central nuclei, and also showed that both type I and type II fibres were equally involved in the disease (Sher et al., 1967; Bethlem, Meijer, Schellens, and Vroom, 1968; Kinoshita and Cadman, 1968; Case II-6 of Wijngaarden et al., 1969).

In other cases the histological picture has been less uniform, with one population of fibres being atrophic, while another is normal in size or even hypertrophic. The larger fibres have usually been predominantly type II in histochemical character, but there have been differences in the characteristics of the atrophic fibres. Engel, Gold, and Karpati (1968) showed with both 'normal' and EDTAreversed myosin ATPase as well as with stains for oxidative enzymes that the peripheral myofibrilcontaining areas of all these fibres in their case were type $I$ in nature. The cases of Bethlem et al. (1969) and Badurska, Fidzianska, Kamieniecka, Prot, and Strugalska (1969) were somewhat similar. However five of the six cases of Wijngaarden et al. (1969), and the case of Bethlem et al. (1970) had atrophic fibres with the peripheral myofibril-containing areas staining lightly both for myosin ATPase, and oxidative enzymes, that is, they were of neither fibre type.

These two or more histological patterns may simply represent different stages in the same process, but they may also indicate the presence of different disease entities. The one histological feature common to all, the central nuclei with perinuclear loss of myofibrils, was not evident in illustrations of four cases reported by Ortiz de Zarate and Maruffo (1970), and for this reason we are not convinced that they should be included in this group of diseases.

The preferential involvement of one fibre type led Engel to suggest that the disease in his patient was a primary damage of the motor neurones innervating type I fibres (Engel et al., 1968; Engel, 1970). The finding of numerous central nuclei in the muscles of animals with botulinum intoxication might be used to support this hypothesis (Duchen, 1970). Similarly the brother of the case of Bethlem et al. (1969) had a distal sensorimotor neuropathy, and the electromyogram of one of the cases of Wijngaarden et al. (1969) suggested a neurogenic lesion. However, the evidence for this hypothesis is at present tenuous.

Spiro et al. (1966) originally suggested that the myopathy resulted from persistence of foetal myotubes into postnatal life, a theory taken up by several other workers. There are reasons for doubting this hypothesis. If it were true, the condition would be expected to be static, whereas many patients have a progressive degenerative course, like the two brothers reported here. Moreover, the fibres with central nuclei are much larger than foetal myotubes. Electron microscopy has shown degenerative changes in some cases (Spiro et al., 1966; Sher et al., 1967; Campbell, Rebeiz, and Walton, 1969), though not in others (Bethlem et al., 1968; Badurska et al., 1969). The three-fold fall in the number of central nuclei in the left gastrocnemius muscle of case 1 of this report during the 17 years between biopsy and death, might suggest nuclear degeneration and loss since approximately the same proportion of fibres had central loss of myofibrils 
TABLE 1

SUMMARY OF FEATURES OF 19 COLLECTED CASES OF CENTRONUCLEAR MYOPATHY

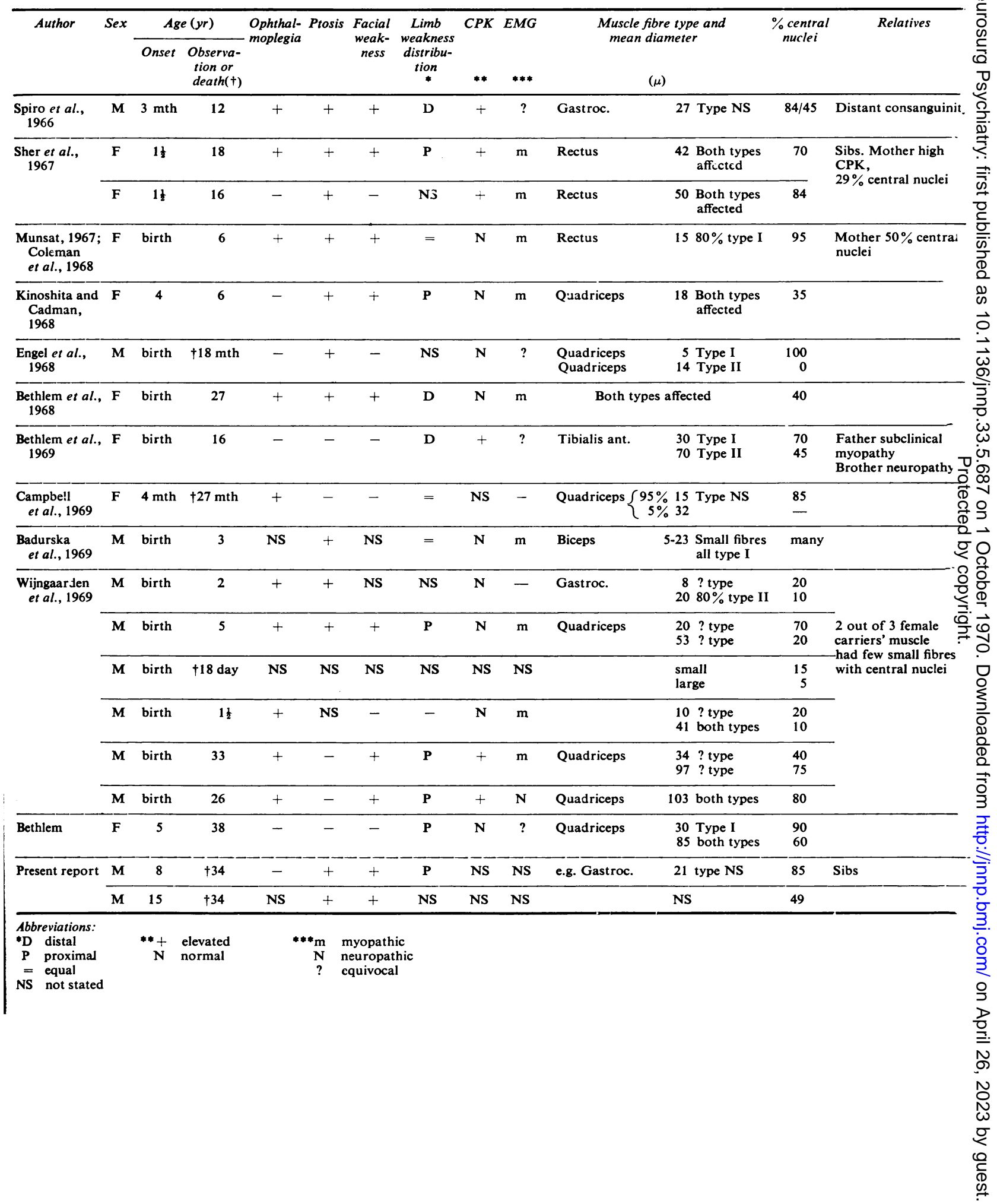


TABLE 2

COMPARISON OF MEAN MUSCLE FIBRE DIAMETERS IN CASE 1 AND CONTROLS

\begin{tabular}{|c|c|c|c|c|}
\hline \multicolumn{2}{|c|}{ Muscle } & \multirow[t]{2}{*}{ Case 1} & \multicolumn{2}{|c|}{ Controls } \\
\hline & & & $a$ & $b$ \\
\hline \multicolumn{2}{|c|}{ Gastrocnemius biopsy } & $20 \cdot 8$ & & \\
\hline & necropsy $\mathbf{R}$ & $7 \cdot 5$ & $57 \cdot 5$ & $47 \cdot 5$ \\
\hline & necropsy $L$ & $16 \cdot 7$ & & \\
\hline \multirow[t]{2}{*}{ Quadriceps } & necropsy $\mathbf{R}$ & $21 \cdot 0$ & & $49 \cdot 1$ \\
\hline & necropsy $\mathbf{L}$ & $23 \cdot 3$ & & \\
\hline Deltoid & $\begin{array}{l}\text { necropsy } \\
\text { necropsy }\end{array}$ & $\begin{array}{l}23.4 \\
25.5\end{array}$ & & $37 \cdot 2$ \\
\hline
\end{tabular}

a. Four male necropsy cases (M. Moore, 1969 ; personal communication)

b. One female necropsy case (W. Aherne, 1970; personal communication)

in both specimens. These points, taken with the extensive endomysial fibrosis, make it more likely that these diseases with central nucleation are degenerative with reversion to a myotubular form, rather than due to a maturation arrest.

We are indebted to Dr. Livia Ross, who performed the necropsy on case 1 , for her interest and stimulation.

\section{REFERENCES}

Badurska, B., Fidzianska, A., Kamieniecka, Z., Prot, J., and Strugalska, H. (1969). Myotubular myopathy. J. neurol. Sci., 8, 563-571.

Bethlem, J., Meijer, A. E. F. H., Schellens, J. P. M., and Vroom, J. J. (1968). Centronuclear myopathy. Europ. Neurol., 1, 325-333.
Bethlem, J., van Wijngaarden, G. K., Meijer, A. E. F. H., and Hülsmann, W. C. (1969). Neuromuscular disease with type I fibre atrophy, central nuclei and myotubelike structures. Neurol. (Minneap.), 19, 705-710.

Bethlem, J., van Wijngaarden, G. K., Mumenthaler, M., and Meijer, A. E. F. H. (1970). Centronuclear myopathy with type I fibre atrophy and 'myotubes'. Arch. Neurol. (Chic.), In press.

Campbell, M. J., Rebeiz, J. J., and Walton, J. N. (1969). Myotubular, centronuclear or peri-centronuclear myopathy? J. neurol. Sci., 8, 425-443.

Coleman, R. F., Thompson, L. R., Niehuis, A. W., Munsat, T. L., and Pearson, C. M. (1968). Histochemical investigation of 'myotubular' myopathy. Arch. Path., 86, 365-376.

Duchen, L. W. (1970). Changes in motor innervation and cholinesterase localization induced by botulinum toxin in skeletal muscle of the mouse. J. Neurol. Neurosurg. Psychiat., 33, 40-54.

Engel, W. K. (1970). Selective and non-selective susceptibility of muscle fibre types. Arch. Neurol. (Chic.), 22, 97-117.

Engel, W. K., Gold, G. N., and Karpati, G. (1968). Type I fibre hypotrophy and central nuclei. A rare congenital muscle abnormality with a possible experimental model. Arch. Neurol. (Chic.), 18, 435-444.

Kinoshita, M., and Cadman, T. E. (1968). Myotubular myopathy. Arch. Neurol. (Chic.), 18, 265-271.

Munsat, T. L. (1967). In U.C.L.A. Interdepartmental Conference: skeletal muscle. Ann. intern. Med., 67, 643646.

Ortiz de Zarate, J. C., and Maruffo, A. (1970). The descending ocular myopathy of early childhood. Myotubular or centronuclear myopathy. Europ. Neurol., 3, 1-12.

Sher, J. H., Rimalovski, A. B., Athanassiades, T. J., and Aronson, S. M. (1967). Familial centronuclear myopathy: a clinical and pathological study. Neurol. (Minneap.), 17, 727-742.

Spiro, A. J., Shy, G. M., and Gonatas, N. K. (1966). Myotubular myopathy. Persistence of fetal muscle in an adolescent boy. Arch. Neurol. (Chic.), 14, 1-13.

Wijngaarden, G. K. van, Fleury, P., Bethlem, J., and Meijer, A. E. F. H. (1969). Familial 'myotubular' myopathy. Neurology (Minneap.), 19, 901-908. 